\title{
Novel analytical approach for brominated flame retardants based on the use of gas chromatography-atmospheric pressure chemical ionization-tandem mass spectrometry with emphasis in highly brominated congeners
}

\author{
Tania Portolés ${ }^{1 *}$, Carlos Sales ${ }^{1}$, Belén Gómara ${ }^{2}$, Juan Vicente Sancho ${ }^{1}$, Joaquim Beltrán ${ }^{1}$, \\ Laura Herrero², María José González², Félix Hernández ${ }^{1}$ \\ ${ }^{1}$ Research Institute for Pesticides and Water, University Jaume I, 12071 Castellón, Spain. \\ ${ }^{2}$ Institute of General Organic Chemistry, CSIC, Madrid, Spain
}

\begin{abstract}
The analysis of brominated flame retardants (BFRs) commonly relies on the use of gas chromatography coupled to mass spectrometry (GC-MS) operating in electron ionization (EI) and electron capture negative ionization (ECNI) modes using quadrupole, triple quadrupole, ion trap, and/or magnetic sector analyzers. However, these brominated contaminants are examples of compounds for which a soft and robust ionization technique might be favourable since they show high fragmentation in EI and low specificity in ECNI. In addition, the low limits of quantification $(0.01 \mathrm{ng} / \mathrm{g})$ required by European Commission Recommendation 2014/118/EU on the monitoring of traces of BFRs in food put stress on the use of highly sensitive techniques/methods. In this work, a new approach for the extremely sensitive determination of BFRs taking profit of the potential of atmospheric pressure chemical ionization (APCI) combined with GC and triple quadrupole (QqQ) mass analyser is proposed. The objective was to explore the potential of this approach for the BFRs determination in samples at pg/g levels, taking marine samples and a cream sample as a model. Ionization and fragmentation behaviour of fourteen PBDEs (congeners 28, 47, 66, 85, 99, $100,153,154,183,184,191,196,197$, and 209) and two novel BFRs, decabromodiphenyl ethane (DBDPE) and 1,2bis(2,4,6-tribromophenoxy)ethane (BTBPE), in the GC-APCI-MS system has been investigated. The formation of highly abundant (quasi) molecular ion was the main advantage observed in relation to EI. Thus, a notable improvement in sensitivity and specificity was observed when using it as precursor ion in tandem MS. The improved detectability (LODs $<10 \mathrm{fg}$ ) achieved when using APCI compared to EI has been demonstrated, which is especially relevant for highly brominated congeners. Analysis of samples from an inter-comparison exercise and samples from the marine field showed the potential of this approach for the reliable identification and quantification at very low concentration levels.
\end{abstract}

Brominated flame retardants (BFRs) are used in a variety of products, such as housing and wiring of TV sets, computers and mobile phones, in electrical kitchen appliances, textiles, building materials, and many plastic products, to reduce their flammability. Thus, exposure to BFRs may occur in many situations in daily life. Due to the fact that most BFRs are persistent, bioaccumulative, and toxic or neurotoxic, the European Union (EU) has taken actions as regards the use and applications of BFRs banning the use of polybrominated diphenyl ether (PBDEs) mixtures (Penta-BDE and Octa-BDE mixtures) in 2004, and Deca-BDE mixture in electric and electronic products in 2009. In addition, limits have been set for PentaBDE and Octa-BDE in products placed on the market. As a result of bans, the use of novel BFRs, such as decabromodiphenyl ethane (DBDPE) and 1,2bis(2,4,6-tribromophenoxy)ethane (BTBPE), used in replacement of Deca-BDE and Octa-BDE mixtures, respectively, and the use of organophosphorus flame retardants is increasing ${ }^{1-3}$. Several reviews have reported the analytical methods commonly used for the determination of PBDEs in environmental and biological matrices ${ }^{4-10}$. Gas chromatography (GC) coupled to mass spectrometry (MS) operating in both electron ionization (EI) and electron capture negative ionization (ECNI) modes using quadrupole $(\mathrm{Q})$, triple quadrupole (QqQ) or ion trap (IT) analyzers are the techniques most widely used 2,11-15. GC-EI-MS methods are readily suitable for quantifying $\mathrm{Br}_{1-7}$ BDEs in environmental and biological samples, but are not on purpose for higher brominated analogues $\left(\mathrm{Br}_{8-10} \mathrm{BDEs}\right)$, and further research should be directed towards the improvement of accuracy and sensitivity for highly brominated BDE congeners. GC-EI-MS is prone to interferences from other chemicals with similar structures (especially polychlorinated biphenyls, PCBs), which may affect the quality of analytical data. GC-ECNI-MS shows higher sensitivity than with EI (especially for high 
brominated PBDEs) and can avoid chlorinated interferences. However, ECNI mass spectra are mainly dominated by the two ions of bromine $(\mathrm{m} / \mathrm{z} 79$ and 81), which difficult discrimination of PBDE congeners from different homolog groups, and among any bromo-compounds ${ }^{2}$.

The higher selectivity and sensitivity offered by GC-EI-MS/MS with QqQ and IT might be a good alternative to the other MS modes, as less matrix effects and interferences from PCBs are commonly observed. However, despite the higher detection specificity, co-eluting PBDE congeners with higher bromine content could still rise to isobaric precursor and fragment ions, which would contribute false signals to the MS/MS channel monitored for a specifically targeted PBDE. In addition, EI ionization produces high fragmentation of compounds making difficult to select specific and/or abundant precursor ions. This fact compromises the selectivity and sensitivity of the MS/MS method ${ }^{4}$.

GC coupled with high resolution MS (GC-HRMS) using magnetic sectors has better sensitivity for the higher brominated congeners and can eliminate interferences between chlorinated and brominated compounds and also among brominated congeners. To this aim is necessary increasing the resolution until 24000 FWHM, which is not appropriate from the sensitivity point of view due to the significant loss of sensitivity. Moreover, the high acquisition and maintenance costs of these instruments make this technique not much accessible for most laboratories ${ }^{4}$.

Recently, the European Commission has published a recommendation urging the European Member to perform monitoring on the presence of brominated flame retardants in a wide variety of individual foodstuffs at limits of quantification extraordinarily low, mostly set-up at $0.01 \mathrm{ng} / \mathrm{g}{ }^{16}$. This will imply great difficulties for the laboratories to get the sensitivity required to reach such a low concentrations in complex-matrix samples as eggs, milk, meat, animal and vegetable fats and oils, fish, and food for infants and small children. Difficulties will be even higher for highly brominated congeners (e.g. BDE 209). The recently revived atmospheric pressure chemical ionization (APCI) source has been satisfactorily applied for GC-amenable compounds such as pesticides, polycyclic aromatic hydrocarbons (PAHs), PCBs and, very recently, dioxins and dioxinlike PCBs and flame retardants ${ }^{17-21}$. The soft ionization generated by this source promotes the formation of the molecular ion and/or the protonated molecule, commonly as the base peak of the spectrum, with poor fragmentation in comparison to the high fragmentation degree generally observed under EI. This is particularly relevant for compounds that suffer extensive fragmentation in EI, and for which the molecular ion used is present with low abundance (e.g most PBDEs). The use of GC-APCI-MS/MS allows the selection of sensitive and specific precursor ion for selected reaction monitoring (SRM) transitions, which leads to a notable increase in sensitivity and selectivity of the analytical method.
In the present study, the potential of GC-MS/MS using QqQ with APCI source has been explored for the extreme sensitive determination of brominated flame retardants as PBDEs, BTBPE, and DBDPE in complex matrices. Special attention has been paid to the optimization of ionization and the selection of appropriate SRM transitions to improve both sensitivity and selectivity. The developed approach has been tested in real-world samples in order to illustrate the possibilities of this technique in the near future.

\section{EXPERIMENTAL}

Reagents. All reagents used for the analysis of PBDEs were of trace analysis grade. Sulphuric acid (95-97\%) and silica gel were supplied by Merck Co. (Darmstadt, Germany). Acetone, $n$-hexane, toluene and granular anhydrous sodium sulphate were obtained from J.T. Baker (Deventer, The Netherlands). All standards were purchased from Wellington Laboratories (Ontario, Canada). A total of 14 PBDE congeners from tri- to deca-BDEs, numbers 28 (2,4,4'-tri-BDE), $47 \quad\left(2,2^{\prime}, 4,4^{\prime}\right.$-tetra-BDE $), 66$ (2,3',4,4'-tetra-BDE), 85 (2,2',3,4,4'-penta-BDE), 99

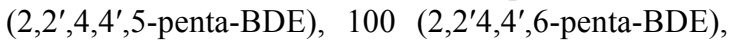
$153\left(2,2^{\prime}, 4,4^{\prime}, 5,5^{\prime}\right.$-hexa-BDE $), \quad 154 \quad\left(2,2^{\prime}, 4,4^{\prime}, 5,6^{\prime}-\right.$ hexa-BDE), $183\left(2,2^{\prime}, 3,4,4^{\prime}, 5^{\prime}, 6\right.$-hepta-BDE $), \quad 184$ $\left(2,2^{\prime}, 3,4,4^{\prime}, 6,6^{\prime}\right.$-hepta-BDE), $191 \quad\left(2,3,3^{\prime}, 4,4^{\prime}, 5^{\prime}, 6-\right.$

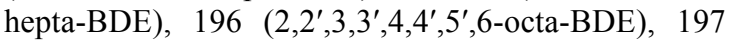
$\left(2,2^{\prime}, 3,3^{\prime}, 4,4^{\prime}, 6,6^{\prime}\right.$-octa-BDE), and 209 $\left(2,2^{\prime}, 3,3^{\prime}, 4,4^{\prime}, 5,5^{\prime}, 6,6^{\prime}\right.$-deca-BDE) and two novel BFRs (BTBPE and DBDPE) were considered. Three ${ }^{13} \mathrm{C}_{12}$-labeled standards, PBDEs 47, 99, 153, were used as surrogate standards for the quantification of samples.

Real samples. A cream sample belonging to the "Interlaboratory Comparison on Dioxins in Food" organized by the Norwegian Institute of Public Health in 2008, and 11 samples from the marine field (1 dolphin, 4 fishes of different sizes, 2 prawns, 2 squids, and 2 zooplankton) were used for the evaluation of the applicability of the developed method.

Sample treatment. Sample extraction and purification procedures have been previously described in the literature, where recoveries of the extraction procedure for labeled $\mathrm{BDE}$ congeners ${ }^{13} \mathrm{C}_{12^{-}}$ BDEs 47, 99, and 153, added to samples before the extraction step, were found to be higher than $65 \%{ }^{22,23}$. Briefly, extraction involved matrix solid-phase dispersion (MSPD); 6-200 g fresh sample homogenized with 4:1 (w/w) silica gel/anhydrous sodium sulfate powder, and spiked with ${ }^{13} \mathrm{C}_{12}$-PBDEs 47,99 , and 153 , was ground to a fine powder, loaded onto a column, and extracted with $400 \mathrm{~mL}$ of $1: 1(\mathrm{v} / \mathrm{v})$ acetone $/ n$-hexane mixture. For the clean-up of the extracts two multilayer columns filled with neutral silica, silica modified with sulfuric acid $(44 \%$, w/w), and silica modified with $\mathrm{KOH}(56 \%$, w/w) were employed using $n$-hexane as elution solvent. When required, the final extract containing the target compounds was subjected to further fractionation on Supelclean $^{\mathrm{TM}}$ ENVI $^{\mathrm{TM}}$-Carb SPE cartridges, as described elsewhere ${ }^{24}$ to separate ortho-substituted 
PCBs plus PBDEs from $\mathrm{PCDD} / \mathrm{Fs}$ and non-orthosubstituted PCBs.

Instrumentation. GC-APCI-MS/MS. Data were acquired using a GC system (Agilent 7890A, Palo Alto, CA, USA) equipped with an autosampler (Agilent 7693) and coupled to a triple quadrupole (QqQ) mass spectrometer (Xevo TQ-S, Waters Corporation, Manchester, UK), operating in positive APCI mode. A fused silica capillary column of $15 \mathrm{~m}$ $\times 0.25 \mathrm{~mm}$ i.d. and a film thickness of $0.1 \mu \mathrm{m}(\mathrm{J} \& \mathrm{~W}$ Scientific, Folson, CA, USA), and using a stationary phase of $100 \%$ methyl polysiloxane (DB-1HT), which can hold temperatures higher than the $300{ }^{\circ} \mathrm{C}$ required to elute high brominated PBDEs, was used for GC separation. The injector was operated in pulsed splitless mode (50 psi, $1 \mathrm{~min}$ ), injecting $1 \mu \mathrm{L}$ at 280 ${ }^{\circ} \mathrm{C}$. The oven temperature was programmed as follows: $140{ }^{\circ} \mathrm{C}(1 \mathrm{~min}) ; 10{ }^{\circ} \mathrm{C} / \mathrm{min}$ to $200{ }^{\circ} \mathrm{C} ; 20$ ${ }^{\circ} \mathrm{C} / \mathrm{min}$ to $300{ }^{\circ} \mathrm{C} ; 40{ }^{\circ} \mathrm{C} / \mathrm{min}$ to $350{ }^{\circ} \mathrm{C}(1 \mathrm{~min})$. Helium was used as carrier gas in constant flow mode (4 $\mathrm{mL} / \mathrm{min}$ ). In the SRM method, automatic dwell time ( 9 to $46 \mathrm{~ms}$ ) was applied in order to obtain 15 points per peak.

The interface temperature was set to $340{ }^{\circ} \mathrm{C}$ using $\mathrm{N}_{2}$ as auxiliary gas at $250 \mathrm{~L} / \mathrm{hr}$, make-up gas at 300 $\mathrm{mL} / \mathrm{min}$ and cone gas at $170 \mathrm{~L} / \mathrm{hr}$. The APCI corona discharge pin was operated at $1.6 \mu \mathrm{A}$. The ionization process occurred within an enclosed ion volume, which enabled control over the protonation/charge transfer processes. Water used as modifier when working under proton-transfer conditions was placed in an uncapped vial, which was located within a specially designed holder placed in the source door. Targetlynx (a module of MassLynx) was used to process the acquired data.

GC-EI-MS/MS. EI analyses were performed on a TRACE GC Ultra gas chromatograph (Thermo Fisher Scientific) coupled triple quadrupole analyser (TSQ Quantum XLS, Thermo Fisher Scientific). More information can be found in Supporting Information.

\section{RESULTS AND DISCUSSION}

Ionization and fragmentation behaviour of PBDEs, BTBPE and DBDPE in GC-APCI and GC-EI coupled to $M S$ with triple quadrupole analyzer. In EI the major ions formed from PBDEs are normally the $[\mathrm{M}]^{+}$and $\left[\mathrm{M}-\mathrm{Br}_{2}\right]^{+\cdot}$, which are useful for identification purposes. Abundances of $[\mathrm{M}]^{+\bullet}$ and $\left[\mathrm{M}-\mathrm{Br}_{2}\right]^{+\bullet}$ decrease with increasing bromine substituents being this effect more drastic in the case of BDE 209 (Figure 1, bottom).For tri- and tetra-BDE congeners, the most abundant ions correspond to the molecular ion cluster and low fragmentation is observed. Moreover, the EI spectra for penta- to decaBDEs are generally dominated by the cluster corresponding to the loss of two bromine atoms except for non-ortho brominated congeners, which have a particularly abundant $[\mathrm{M}]^{+\bullet}$, but almost no [M$\left.\mathrm{Br}_{2}\right]^{+\cdot 2,4,11,25,26}$.

In this work, the "soft" ionization behavior of the APCI interface was tested using PBDEs, BTBPE and DBDPE standards in solvent. Two mechanisms of ionization were observed: i) charge transfer in which the nitrogen plasma created by the corona discharge needle promotes the formation of $\mathrm{M}^{+\cdot}$, and ii) proton

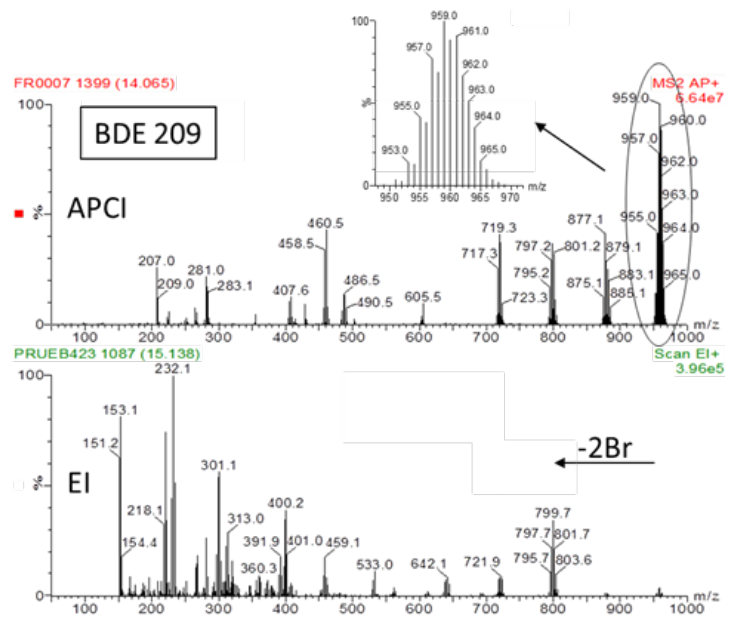

transfer, where the presence of water vapor traces in the source favors the formation of the $[\mathrm{M}+\mathrm{H}]^{+}$ion.

The PBDEs studied showed a mixture of two isotopic patterns corresponding to $\mathrm{M}^{+\bullet}$ and $[\mathrm{M}+\mathrm{H}]^{+}$as base peak of the spectrum. Figure 1 (up) shows the APCI spectrum of BDE 209, where a cluster corresponding to both isotopic clusters of $\mathrm{M}^{+\cdot}$ and $[\mathrm{M}+\mathrm{H}]^{+}$can be observed as base peak of the spectrum,

Figure 1. APCI (top) and EI (bottom) spectrum of BDE 209.

although water had not been added in the source. The bromination degree affected to the behavior of the compound under APCI. In the case of $\mathrm{Br}_{3-4} \mathrm{BDEs}$, the $[\mathrm{M}+\mathrm{H}]^{+}$intensity was higher than $\mathrm{M}^{+}$. In contrast, for $\mathrm{Br}_{5-10}$ BDEs, the intensity of $\mathrm{M}^{+\bullet}$ was slightly higher than $[\mathrm{M}+\mathrm{H}]^{+}$and increased with increasing bromine substituents. APCI mass spectrum of BTBPE also showed a mixture of the isotopic patterns corresponding to $\mathrm{M}^{+\bullet}$ and $[\mathrm{M}+\mathrm{H}]^{+}$(although in this case not as base peak). For DBDPE $\left(\mathrm{C}_{14} \mathrm{H}_{4} \mathrm{Br}_{10}\right)$, the base peak was a fragment corresponding to the ion $\mathrm{C}_{8} \mathrm{H}_{4} \mathrm{Br}_{5}{ }^{+\bullet}$ and neither $\mathrm{M}^{+\bullet}$ nor $[\mathrm{M}+\mathrm{H}]^{+}$was observed.

Cone voltage between 5 and $50 \mathrm{~V}$ was tested in order to select the optimum value for each compound considering the possibility that in-source fragmentation can occur, especially at higher cone voltages. No significant differences on in-source fragmentation pattern were observed, but voltages higher than $40 \mathrm{~V}$ generally led to a loss of abundance of the molecular ion and/or protonated molecule without increasing the abundance of mass fragments. For each compound, the cone voltage that gave the highest intensity for the quasi-molecular ion (typically $20 \mathrm{~V}$ ) was selected for further experiments.

Finally, the fragmentation of the PBDEs, BTBPE, and DBDPE in the collision cell was studied. $[\mathrm{M}]^{+}$, $[\mathrm{M}+2]^{+\bullet}$ and $[\mathrm{M}+4]^{+\bullet}$ were selected as precursor ions for $\mathrm{Br}_{3-4} \mathrm{BDEs} ;[\mathrm{M}+2]^{+\bullet},[\mathrm{M}+4]^{+\bullet}$ and $[\mathrm{M}+6]^{+\bullet}$ for $\mathrm{Br}_{5-6}$ BDEs; $[\mathrm{M}+4]^{+\bullet},[\mathrm{M}+6]^{+\bullet}$ and $[\mathrm{M}+8]^{+\bullet}$ for $\mathrm{Br}_{7-10}$ BDEs. Fragmentation was performed at collision energies between 5-60 eV. The losses of $\mathrm{Br}_{2}$ and $\mathrm{Br}_{2}+\mathrm{CBrO}$ 
were the most abundant and common to all PBDEs studied. Moreover, the loss of $\mathrm{Br}_{4}$ was also observed for $\mathrm{Br}_{5-10} \mathrm{BDEs}, \mathrm{Br}_{4}+\mathrm{CO}$ for $\mathrm{Br}_{4-5} \mathrm{BDEs}$, and $\mathrm{Br}_{5}+\mathrm{CO}$ for $\mathrm{Br}_{5-6}$ BDEs. BTBPE showed the losses of $\mathrm{C}_{6} \mathrm{H}_{2} \mathrm{Br}_{3} \mathrm{O}, \mathrm{C}_{6} \mathrm{H}_{2} \mathrm{Br} \mathrm{r}_{4} \mathrm{O}$, and $\mathrm{C}_{6} \mathrm{H}_{2} \mathrm{Br}_{4} \mathrm{O}_{2}$ from the ions $[\mathrm{M}+2]^{+*},[\mathrm{M}+4]^{+\bullet}$ and $[\mathrm{M}+6]^{+\bullet}$. DBDPE showed the losses of $\mathrm{Br}, \mathrm{Br}_{2}$, and $\mathrm{Br}_{3}$ from the fragment ion $\left(\mathrm{C}_{8} \mathrm{H}_{4} \mathrm{Br}_{5}{ }^{+\bullet}\right)$ selected as precursor $\left([\mathrm{F}+2]^{+\bullet},[\mathrm{F}+4]^{+\bullet}\right.$ and $\left.[\mathrm{F}+6]^{+*}\right)$. As an illustrative example, Figure $\mathrm{S}-1 \mathrm{~A}$ shows the APCI product ion spectra for $\mathrm{M}^{+\bullet}$ (charge transfer conditions) of BDE 47 (top) and BDE 209 (down) at different collision energies.

Effect of added modifiers on the ionization and fragmentation behaviour of PBDEs, BTBPE and DBDPE in GC-APCI-MS/MS with QqQ. As explained above, both $[\mathrm{M}+\mathrm{H}]^{+}$and $\mathrm{M}^{+\bullet}$ were observed on APCI spectra of all PBDEs even under "dry" conditions. This fact encouraged us to introduce water as a modifier to promote the formation of the protonated molecule. Water was added on purpose and the presence/absence and/or improvement on the signal of the protonated molecule was evaluated. The modifier was placed in an uncapped vial, located within a specially designed holder in the source door.

The use of water as modifier favored the formation of the $[\mathrm{M}+\mathrm{H}]^{+}$and the $\mathrm{M}^{+\bullet}$ disappeared in most cases, increasing the proportion of $[\mathrm{M}+\mathrm{H}]^{+}$. These occurred for all the PBDEs studied except for the $\mathrm{Br}_{7-10} \mathrm{BDEs}$ and BTBPE for which a low percentage of $\mathrm{M}^{+\bullet}$ still appeared in their spectra. Protonation degree was improved for the BTBPE and $\mathrm{Br}_{7-10}$ BDEs adding aqueous $1 \% \mathrm{HCOOH}$ as modifier. The spectrum of DBDPE did not change when adding modifiers to the source, maintaining the fragment indicated before as base peak.

Next, the PBDEs fragmentation in the collision cell was studied, after selection of the protonated molecule as precursor ion. The quasi-molecular ion $[\mathrm{M}+\mathrm{H}]^{+}$, $[\mathrm{M}+\mathrm{H}+2]^{+}$, and $[\mathrm{M}+\mathrm{H}+4]^{+}$were selected as precursor ions for $\mathrm{Br}_{3-4}$ BDEs; $[\mathrm{M}+\mathrm{H}+2]^{+},[\mathrm{M}+\mathrm{H}+4]^{+}$, and $[\mathrm{M}+\mathrm{H}+6]^{+}$for $\mathrm{Br}_{5-6} \mathrm{BDEs}$; and $[\mathrm{M}+\mathrm{H}+4]^{+},[\mathrm{M}+\mathrm{H}+6]^{+}$, and $[\mathrm{M}+\mathrm{H}+8]^{+}$for $\mathrm{Br}_{7-10}$ BDEs. Again, fragmentation was performed at collision energies in the range 5-60 $\mathrm{eV}$. The losses of $\mathrm{Br}$ and $\mathrm{Br}_{3}$ were the most abundant and common to all PBDEs. The loss of $\mathrm{CHBr}_{3} \mathrm{O}$ was observed for tri-BDEs, and the loss of $\mathrm{CBr}_{4} \mathrm{O}$ for tetra- and penta- BDEs. BTBPE showed losses of $\mathrm{C}_{6} \mathrm{H}_{2} \mathrm{Br}_{3} \mathrm{O}, \quad \mathrm{C}_{6} \mathrm{H}_{2} \mathrm{Br}{ }_{3} \mathrm{O}+\mathrm{Br}, \quad \mathrm{C}_{6} \mathrm{H}_{2} \mathrm{Br} \mathrm{r}_{3} \mathrm{O}+\mathrm{COBr}$, and $\mathrm{C}_{6} \mathrm{H}_{2} \mathrm{Br}_{3} \mathrm{O}+\mathrm{Br}+\mathrm{COBr}$ from $[\mathrm{M}+\mathrm{H}+2]^{+}, \quad[\mathrm{M}+\mathrm{H}+4]^{+}$, and $[\mathrm{M}+\mathrm{H}+6]^{+}$. DBDPE showed the losses of $\mathrm{CH}_{2}$, $\mathrm{Br}, \mathrm{Br}_{2}$, and $\mathrm{Br}_{3}$ from the fragment ion selected $\mathrm{C}_{8} \mathrm{H}_{4} \mathrm{Br}_{5}^{+\bullet}\left([\mathrm{F}+2]^{+\cdot},[\mathrm{F}+4]^{+\bullet}\right.$, and $\left.[\mathrm{F}+6]^{+\bullet}\right)$. As an example, Figure S-1B shows the APCI product ion spectra for $[\mathrm{M}+\mathrm{H}]^{+}$(proton transfer conditions, $1 \%$ $\mathrm{HCOOH}$ as modifier) of BDE 47 (top) and BDE 209 (down) at different collision energies. The selected reaction monitoring (SRM) transitions optimized for each compound are shown in Table 1.

Sensitivity and repeatability. The sensitivity and repeatability of the GC-MS/MS signals for PBDEs, BTBPE, and DBDPE were evaluated for all the transitions selected (those coming from $\mathrm{M}^{+\cdot}$ as well as from $[\mathrm{M}+\mathrm{H}]^{+}$) under the different conditions (with and without the use of modifiers). Under charge transfer conditions (without adding water), all compounds showed better sensitivity for $\mathrm{M}^{+\bullet}$ transitions being in most cases among 2 and 7 times higher than for $[\mathrm{M}+\mathrm{H}]^{+}$(see Figure 2A). As expected, the sensitivity for all compounds dramatically decreased (around 20 times) for the $\mathrm{M}^{+\bullet}$ transitions when adding water as modifier, while at the same time the intensity for $[\mathrm{M}+\mathrm{H}]^{+}$transitions improved around 1.5 times. This occurred for all the compounds except for $\mathrm{Br}_{6-10} \mathrm{BDEs}$ and DBDPE for which a 2-fold decrease was observed for $[\mathrm{M}+\mathrm{H}]^{+}$. When adding $\mathrm{HCOOH} 1 \%$, the sensitivity of $[\mathrm{M}+\mathrm{H}]^{+}$transitions remained almost the same as with only water. In any case, all the compounds showed the highest sensitivity under charge transfer conditions for the $\mathrm{M}^{+\bullet}$ transitions.

The repeatability of the response $(n=10$ at 25 $\mathrm{ng} / \mathrm{mL}$ ) was also evaluated under the different working conditions (Figure 2B). Data showed a slightly lower repeatability for $\mathrm{M}^{+\bullet}$ transitions when working under charge transfer conditions (relative standard deviations, RSD, bweteen $10-20 \%$ for most compounds) being a bit better for $[\mathrm{M}+\mathrm{H}]^{+}$transitions (RSD 5-20\%). This parameter improved under protontransfer conditions using water as modifier (RSD 5$15 \%$ ) and became even better when the protonation was promoted adding $\mathrm{HCOOH} 1 \%$ (RSD < $10 \%$ ). Therefore, under charge transfer conditions a reproducible mixture of both molecular ion and protonated molecule occurred for most PBDEs, with acceptable RSD.

Specificity of the SRM transitions. Despite the soft ionization occurring in the APCI source, some insource fragments were observed in the full scan spectra of PBDEs. These mainly came from losses of bromine that also correspond to precursor ions of SRM transitions selected for PBDEs showing lower brominated degree. This is important, because potential losses of bromine that also correspond to precursor ions of SRM transitions selected for PBDEs showing lower brominated degree. This is important, because potential interferences from $\mathrm{PCBs}$ can be eliminated, as it already occurred with GC-EI-MS/MS experiments with QqQ and IT and the GC-ECNI-MS. However, this fact might led to loss of specificity of the transitions in case of coelution of PBDEs with different bromine degree, as PBDEs with higher bromination might interfere in the determination of the lower ones, as it already occurred with GC-EIMS/MS experiments with QqQ and IT. This fact only occurred for experiments performed under charge transfer conditions and using the SRM transitions resulting from the use of $\mathrm{M}^{+\bullet}$ as precursor ion. On the contrary, if precursor ions were $[\mathrm{M}+\mathrm{H}]^{+}$, this overlapping did not occur (see Figure S-2). This imply that ion-source fragmentation mainly comes from the $\mathrm{M}^{+*}$; thus, when it is removed by favoring the formation of $[\mathrm{M}+\mathrm{H}]^{+}$its in-source fragments are also eliminated.

Overall, the better sensitivity expected for a SRM method with $\mathrm{M}^{+\cdot}$ transitions under charge-transfer conditions together with acceptable repeatability 
seemed to be a good option for determination of PBDEs at low concentrations. However, the better specificity and repeatability resulting from $[\mathrm{M}+\mathrm{H}]^{+}$ transitions encouraged us to not discard an analytical method based on this option yet. Therefore, further experiments were carried out using both approaches in order to select the best one.

Linearity and LODs. Linearity of relative response of analytes was established by analyzing standards solutions, in triplicate, in the range of $0.2-100$ $\mathrm{ng} / \mathrm{mL}$

Table 1. Experimental conditions of the optimized GC-APCI-QqQ(MS/MS) method for PBDEs and novel BFRs under both, charge and proton transfer conditions

\begin{tabular}{|c|c|c|c|c|c|c|c|c|c|}
\hline & & Charge-tra & onditions & & & Proton-tra & conditions & & \\
\hline Compound & $\begin{array}{l}t_{R} \\
(\min )\end{array}$ & $\begin{array}{l}\text { Precursor } \\
\text { ion } \\
(\mathrm{m} / \mathrm{z})\end{array}$ & $\begin{array}{l}\text { Product } \\
\text { ion } \\
(\mathrm{m} / \mathrm{z})\end{array}$ & $\begin{array}{l}\text { Collision } \\
\text { energy } \\
(\mathrm{eV})\end{array}$ & Loss & $\begin{array}{l}\text { Precursor } \\
\text { ion } \\
(\mathrm{m} / \mathrm{z})\end{array}$ & $\begin{array}{l}\text { Product } \\
\text { ion } \\
(\mathrm{m} / \mathrm{z})\end{array}$ & $\begin{array}{l}\text { Collision } \\
\text { energy } \\
(\mathrm{eV})\end{array}$ & Loss \\
\hline \multirow[t]{6}{*}{ BDE 28} & 3.7 & 403.8 & 246 & 20 & $-\mathrm{Br}_{2}$ & 404.8 & 167.9 & 30 & $-\mathrm{Br}_{3}$ \\
\hline & & & 139 & 30 & $-\mathrm{CBr}_{3} \mathrm{O}$ & 406.8 & 327.9 & 10 & $-\mathrm{Br}$ \\
\hline & & 405.8 & 246 & 20 & $-\mathrm{Br}_{2}$ & & 168.1 & 30 & $-\mathrm{Br}_{3}$ \\
\hline & & & 139 & 30 & $-\mathrm{CBr}_{3} \mathrm{O}$ & 408.8 & 327.9 & 10 & $-\mathrm{Br}$ \\
\hline & & 407.8 & 248 & 20 & $-\mathrm{Br}_{2}$ & & 168.0 & 30 & $-\mathrm{Br}_{3}$ \\
\hline & & & 139 & 30 & $-\mathrm{CBr}_{3} \mathrm{O}$ & & & & \\
\hline${ }^{13} C_{12}-B D E 47$ & 4.82 & 495.5 & 335.8 & 20 & & 496.7 & 258 & 30 & \\
\hline BDE 47 & 4.82 & 481.6 & 323.8 & 20 & $-\mathrm{Br}_{2}$ & 484.7 & 405.8 & 20 & $-\mathrm{Br}$ \\
\hline \multirow[t]{5}{*}{ BDE 66} & 4.97 & 483.6 & 323.8 & 20 & $-\mathrm{Br}_{2}$ & & 246 & 30 & $-\mathrm{Br}_{3}$ \\
\hline & & & 217 & 60 & $-\mathrm{CBr}_{3} \mathrm{O}$ & 486.7 & 405.8 & 20 & $-\mathrm{Br}$ \\
\hline & & 485.6 & 325.8 & 20 & $-\mathrm{Br}_{2}$ & & 246 & 30 & $-\mathrm{Br}_{3}$ \\
\hline & & & 219 & 50 & $-\mathrm{CBr}_{3} \mathrm{O}$ & & 139.1 & 60 & $-\mathrm{CBr}_{4} \mathrm{O}$ \\
\hline & & & 138 & 60 & $-\mathrm{CBr}_{4} \mathrm{O}$ & & & & \\
\hline${ }^{13} C_{12}-B D E 99$ & 5.81 & 575.5 & 415.7 & 30 & & 578.6 & 337.9 & 30 & \\
\hline BDE 100 & 5.6 & 561.5 & 244 & 50 & $-\mathrm{Br}_{4}$ & 562.6 & 483.6 & 20 & $-\mathrm{Br}$ \\
\hline BDE 99 & 5.81 & & 137.1 & 60 & $-\mathrm{CBr}_{5} \mathrm{O}$ & 564.6 & 485.6 & 20 & $-\mathrm{Br}$ \\
\hline \multirow[t]{4}{*}{ BDE 85} & 6.14 & 563.5 & 403.7 & 30 & $-\mathrm{Br}_{2}$ & & 325.9 & 30 & $-\mathrm{Br}_{3}$ \\
\hline & & & 296.9 & 50 & $-\mathrm{CBr}_{3} \mathrm{O}$ & 566.6 & 485.6 & 20 & $-\mathrm{Br}$ \\
\hline & & 565.5 & 405.7 & 30 & $-\mathrm{Br}_{2}$ & & 325.9 & 30 & $-\mathrm{Br}_{3}$ \\
\hline & & & 296.9 & 50 & $-\mathrm{CBr}_{3} \mathrm{O}$ & & & & \\
\hline${ }^{13} C_{12}-B D E 153$ & 6.67 & 655.4 & 495.6 & 30 & & 656.5 & 415.8 & 30 & \\
\hline BDE 154 & 6.39 & 639.4 & 372.8 & 50 & $-\mathrm{CBr}_{3} \mathrm{O}$ & 640.4 & 561.6 & 20 & $-\mathrm{Br}$ \\
\hline \multirow[t]{5}{*}{ BDE 153} & 6.67 & & 321.8 & 60 & $-\mathrm{Br}_{4}$ & 642.4 & 563.6 & 20 & $-\mathrm{Br}$ \\
\hline & & 641.4 & 481.6 & 30 & $-\mathrm{Br}_{2}$ & & 403.8 & 30 & $-\mathrm{Br}_{3}$ \\
\hline & & & 374.8 & 50 & $-\mathrm{CBr}_{3} \mathrm{O}$ & 644.5 & 563.5 & 20 & $-\mathrm{Br}$ \\
\hline & & 643.4 & 483.6 & 30 & $-\mathrm{Br}_{2}$ & & 403.8 & 30 & $-\mathrm{Br}_{3}$ \\
\hline & & & 217 & 60 & $-\mathrm{CBr}_{5} \mathrm{O}$ & & & & \\
\hline BDE 184 & 7.3 & 719.3 & 452.7 & 60 & $-\mathrm{CBr}_{3} \mathrm{O}$ & 720.4 & 641.4 & 20 & $-\mathrm{Br}$ \\
\hline BDE 183 & 7.44 & & 401.8 & 60 & $-\mathrm{Br}_{4}$ & 722.3 & 643.4 & 20 & $-\mathrm{Br}$ \\
\hline \multirow[t]{4}{*}{ BDE 191} & 7.63 & 721.3 & 561.7 & 30 & $-\mathrm{Br}_{2}$ & & 483.6 & 30 & $-\mathrm{Br}_{3}$ \\
\hline & & & 454.7 & 60 & $-\mathrm{CBr}_{3} \mathrm{O}$ & 724.3 & 643.4 & 20 & $-\mathrm{Br}$ \\
\hline & & 723.3 & 563.5 & 30 & $-\mathrm{Br}_{2}$ & & 483.6 & 30 & $-\mathrm{Br}_{3}$ \\
\hline & & & 454.7 & 60 & $-\mathrm{CBr}_{3} \mathrm{O}$ & & & & \\
\hline \multirow[t]{6}{*}{ BTBPE } & 7.69 & 683.5 & 355 & 10 & $-\mathrm{C}_{6} \mathrm{H}_{2} \mathrm{Br}_{3} \mathrm{O}$ & 684.5 & 354.9 & 10 & $-\mathrm{C}_{6} \mathrm{H}_{2} \mathrm{OBr}_{3}$ \\
\hline & & & 275.9 & 30 & $-\mathrm{C}_{6} \mathrm{H}_{2} \mathrm{Br}_{4} \mathrm{O}$ & 686.5 & 356.8 & 10 & $-\mathrm{C}_{6} \mathrm{H}_{2} \mathrm{OBr}_{3}$ \\
\hline & & 685.5 & 357.1 & 10 & $-\mathrm{C}_{6} \mathrm{H}_{2} \mathrm{Br}_{3} \mathrm{O}$ & 688.5 & 357 & 10 & $-\mathrm{C}_{6} \mathrm{H}_{2} \mathrm{OBr}_{3}$ \\
\hline & & & 249.9 & 40 & $-\mathrm{C}_{7} \mathrm{H}_{2} \mathrm{Br}_{4} \mathrm{O}_{2}$ & & 277.9 & 30 & $-\mathrm{C}_{6} \mathrm{H}_{2} \mathrm{OBr}_{4}$ \\
\hline & & 687.5 & 357.1 & 10 & $-\mathrm{C}_{6} \mathrm{H}_{2} \mathrm{Br}_{3} \mathrm{O}$ & & 251.8 & 50 & $-\mathrm{C}_{7} \mathrm{H}_{2} \mathrm{O}_{2} \mathrm{Br}_{4}$ \\
\hline & & & 278.3 & 30 & $-\mathrm{C}_{6} \mathrm{H}_{2} \mathrm{Br}_{4} \mathrm{O}$ & & & & \\
\hline BDE 197 & 8.3 & 797.2 & 530.6 & 60 & $-\mathrm{CBr}_{3} \mathrm{O}$ & 798.2 & 719.7 & 20 & $-\mathrm{Br}$ \\
\hline \multirow[t]{5}{*}{ BDE 196} & 8.47 & & 479.9 & 60 & $-\mathrm{Br}_{4}$ & 800.3 & 721.3 & 20 & $-\mathrm{Br}$ \\
\hline & & 799.2 & 639.5 & 30 & $-\mathrm{Br}_{2}$ & & 561.8 & 40 & $-\mathrm{Br}_{3}$ \\
\hline & & & 532.5 & 60 & $-\mathrm{CBr}_{3} \mathrm{O}$ & 802.3 & 721.6 & 20 & $-\mathrm{Br}$ \\
\hline & & 801.3 & 641.8 & 30 & $-\mathrm{Br}_{2}$ & & 561.5 & 40 & $-\mathrm{Br}_{3}$ \\
\hline & & & 534.5 & 60 & $-\mathrm{CBr}_{3} \mathrm{O}$ & & & & \\
\hline \multirow[t]{6}{*}{ BDE 209} & 9.69 & 955 & 795.2 & 30 & $-\mathrm{Br}_{2}$ & 956.1 & 877.1 & 20 & $-\mathrm{Br}$ \\
\hline & & & 637.4 & 60 & $-\mathrm{Br}_{4}$ & 958.1 & 879.3 & 20 & $-\mathrm{Br}$ \\
\hline & & 957 & 797.2 & 30 & $-\mathrm{Br}_{2}$ & & 719.3 & 40 & $-\mathrm{Br}_{3}$ \\
\hline & & & 637.4 & 60 & $-\mathrm{Br}_{4}$ & 960.1 & 879.2 & 20 & $-\mathrm{Br}$ \\
\hline & & 959 & 799.2 & 30 & $-\mathrm{Br}_{2}$ & & 719.3 & 40 & $-\mathrm{Br}_{3}$ \\
\hline & & & 639.3 & 60 & $-\mathrm{Br}_{4}$ & & & & \\
\hline \multirow[t]{6}{*}{ DBDPE } & 9.94 & 496.4 & 417.5 & 20 & $-\mathrm{Br}$ & 496.4 & 417.5 & 20 & $-\mathrm{Br}$ \\
\hline & & & 338.6 & 30 & $-\mathrm{Br}_{2}$ & & 338.6 & 30 & $-\mathrm{Br}_{2}$ \\
\hline & & & 257.7 & 50 & $-\mathrm{Br}_{3}$ & & 257.7 & 50 & $-\mathrm{Br}_{3}$ \\
\hline & & 498.4 & 419.6 & 20 & $-\mathrm{Br}$ & 498.4 & 419.6 & 20 & $-\mathrm{Br}$ \\
\hline & & & 338.7 & 30 & $-\mathrm{Br}_{2}$ & & 338.7 & 30 & $-\mathrm{Br}_{2}$ \\
\hline & & & 259.9 & 50 & $-\mathrm{Br}_{3}$ & & 259.9 & 50 & $-\mathrm{Br}_{3}$ \\
\hline
\end{tabular}

(for $\mathrm{Br}_{3-8}$ BDEs and BTBPE), $1-500 \mathrm{ng} / \mathrm{mL}$ (BDE 209) and $2-1000 \mathrm{ng} / \mathrm{mL}$ (DBDPE). Data were obtained using both approaches: $\mathrm{M}^{+\bullet}$ transitions under charge-transfer conditions and $[\mathrm{M}+\mathrm{H}]^{+}$transitions under proton-transfer conditions. The correlation coefficients (r) were higher than 0.99 , with residuals lower than $20 \%$ for all the compounds. LODs (signalto-noise ratio 3) were extremely low: between 1-10 fg for the method under charge-transfer conditions, and slightly higher under proton-transfer conditions, 1-25 fg). These values were lower than those previously reported using other ionizations sources(40-41000 fg by GC-EI-MS/MS with QqQ, 280-5200 fg by GC-EIMS/MS with ITD, 6-507 fg by GC-ECNI-MS, or 20$50 \mathrm{fg}$ by GC-EI-HRMS (in this last case only for low brominated PBDEs)) ${ }^{11,13,22,27}$. In contrast to EI-based 
techniques, in our work the sensitivity for these compounds seemed not to be related with the brominating degree, as detectability was similar for all congeners independently of number of bromine atoms.

The improvement in sensitivity obtained is more crucial for the highly brominated BDEs, as the

Absolute sensitivity (peak area)

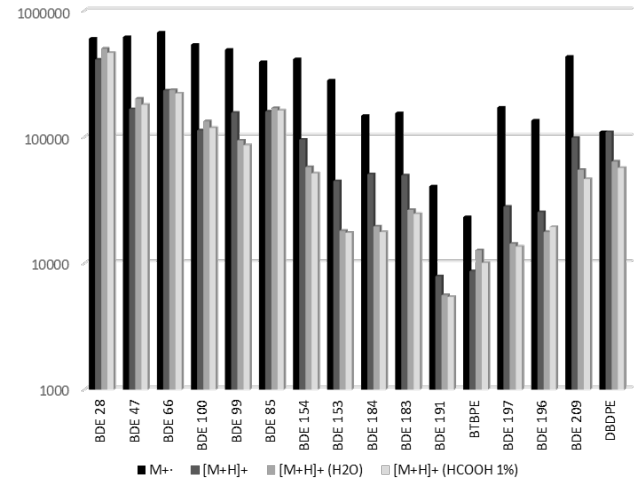

(A) analytical chemistry commonly find problems in reaching the low concentrations required in the legislation. Figure $3 \mathrm{~A}$ shows the excellent sensitivity that can be reached by GC-APCI-MS/MS (charge transfer conditions). At $0.05 \mathrm{ng} / \mathrm{mL}$ (0.05 pg BFRs on-

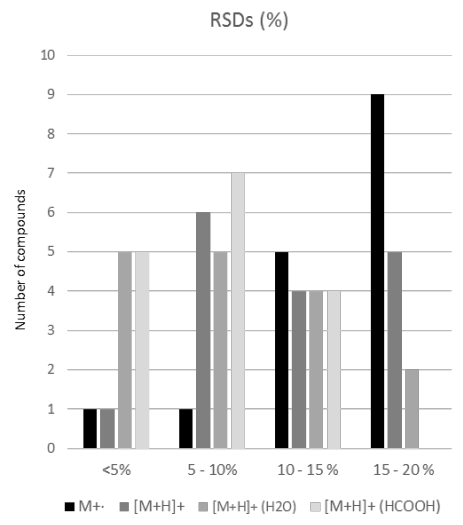

(B)

Figure 2. (A) Absolute sensitivity (logarithmic scale) of PBDEs, BTBPE, and DBDPE under different ionization conditions using different modifiers. (B) Repeatability of the response (\% RSD, $n=10$ ) for PBDEs, BTBPE, and DBDPE under different conditions using different modifiers.

column) $\mathrm{S} / \mathrm{N}$ was still around 100 for all BFRs, except BTBPE (approximately 10 times less sensitive) for which $\mathrm{S} / \mathrm{N}$ was around 20 at $0.1 \mathrm{ng} / \mathrm{mL}$. Similarly, Figure 3B illustrates the, the good sensitivity that can also be reached by GC-APCI-MS/MS (proton transfer conditions), although being a bit lower than in the other option. Under the conditions established in this work, the disadvantages when using other reported techniques can be avoided. In addition, working under GC-APCI-MS/MS the typical interferences coming from PCBs (e.g. in GC-EI-MS) do not exist. The high sensitivity observed for all PBDEs, especially for the higher brominated PBDE congeners (even better than that obtained with GC-ECNI-MS and GC-EI-HRMS), is also a key aspect in the present approach.

Application to the analysis of interlaboratory exercise and marine samples. The two approaches evaluated in this work were finally applied to the analysis of the endogenous PBDE levels in samples belonging to the "Interlaboratory Comparison on Dioxins in Food" organized by the Norwegian Institute of Public Health in 2008. A cream sample was selected since it was contaminated with low levels of PBDEs (from 0.55 to $45 \mathrm{pg} / \mathrm{g}$ fresh weight). The concentrations obtained using the developed methodology were all within the range $(\mid z$-score $\mid<2)$ for all the congeners detected. It is important to note that only a small number of participants in the interlaboratory comparison exercises reported PBDEs data, compared with those that reported $\mathrm{PCBs}$ and $\mathrm{PCDD} / \mathrm{Fs}$. This fact, together with the high variability of the reported data (for some PBDEs with deviations up to $100 \%$ ), illustrates the present difficulties in performing determinations of PBDE congeners in biological and food samples, and the need for accurate, selective, sensitive and low-cost methods, such as those that can result from the present work. Unfortunately, novel BFRs are still not included as target compounds in this type of inter-laboratory exercises, and thus, it was not possible to verify method accuracy for them.

In addition, our methodology was tested for PBDEs and novel BFRs in samples from the marine field. Quantification of the samples was carried out by using calibration curves with standards in solvent, using relative responses to three internal labeled standards added as surrogates to the samples: ${ }^{13} \mathrm{C}_{12}$-BDE 47 for tri-tetra BDEs; ${ }^{13} \mathrm{C}_{12}$-BDE 99 for penta-BDEs, and ${ }^{13} \mathrm{C}_{12}$-BDE 153 for the rest. The results were compared with those obtained by GC-EI-MS/MS (see Table S-1). For the major congeners (PBDEs 28, 47, $99,100,153$, and 154) present in the samples at concentrations above the lowest calibration level (LCL), data were rather similar for both techniques with mean relative errors around $10 \%$, except for a few cases where errors were up to 20 and $30 \%$. For BDE 209, the differences between APCI and EI were notable. While in EI, BDE 209 was detected in 6 out of 11 samples (quantified in 4 of them) the better sensitivity of APCI allowed to detect this compound in 9 out of 11 samples (quantified in 7 of them). The different concentrations reported by the two techniques applied revealed that BDE-209 was more problematic than the other PBDEs analyzed. The fact that none of the internal standards was the labeled BDE-209 surely affected to quantification, although not to the signal intensity, which was notably higher in APCI. More research is required to understand these differences, which were probably due to unknown matrix effects that could not be corrected 
using an appropriate internal standard. Figure 4A shows a positive finding of BDE 209 detected in fish that was not detected under GC-EI-MS/MS. On the contrary, analysis by GC-APCI-MS/MS allowed identification of this compound using up to six SRM transitions (one for quantification and five for confirmation), giving an estimated concentration as low as $26.6 \mathrm{pg} / \mathrm{g}$ (corresponding to $7 \mu \mathrm{g} / \mathrm{L}$ in the extract). The improved method sensitivity for real samples in comparison to previous reported approaches was evident.

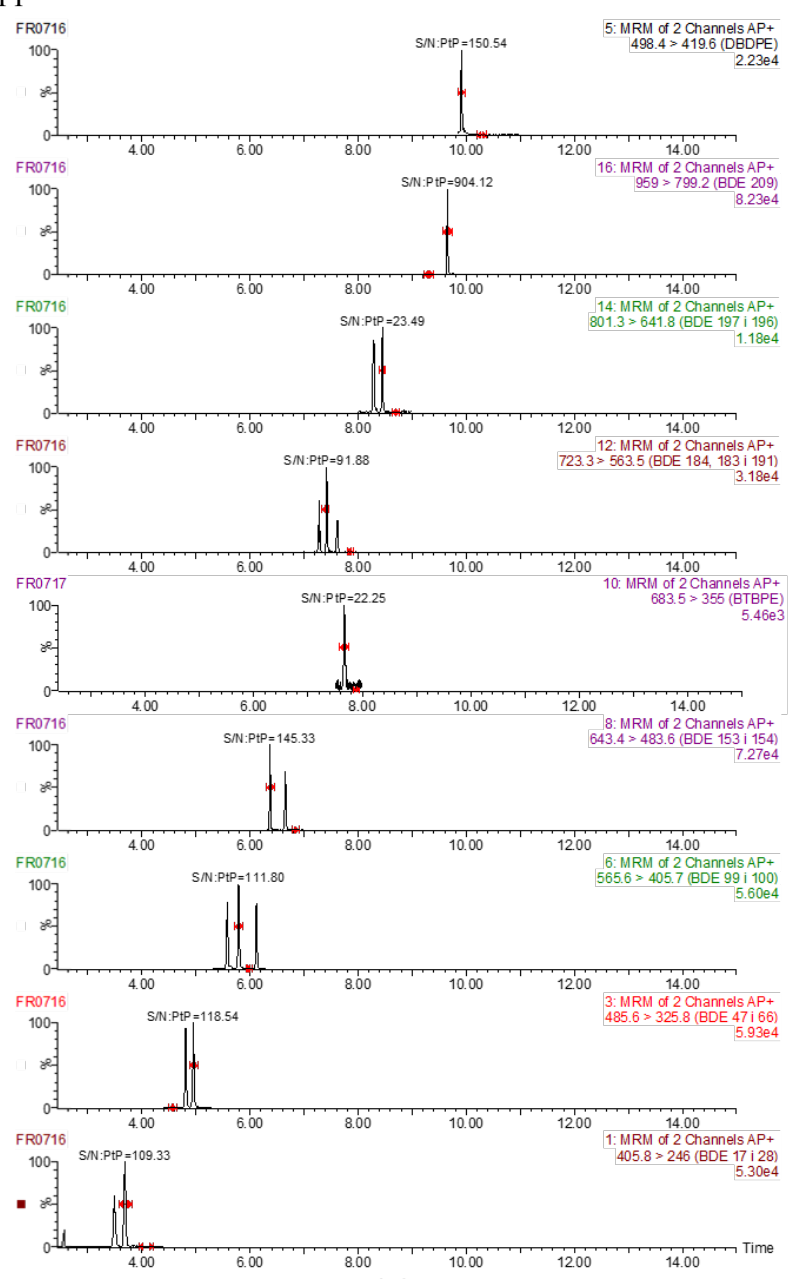

(A)
For the minor congeners (PBDEs 66, 85, 183,184, 191, 196, and 197) and for the novel BFRs (BTBPE and DBDPE), the higher sensitivity resulting from GC-APCI-MS/MS allowed the detection and identification of many of these compounds that had not been detected by GC-EI-MS/MS (see Table S-1). Especially for some BDE congeners (numbers 183, 196, and 197) and also for DBDPE, most of the samples had previously resulted as non-detected, but after re-analysis by GC-APCI-MS/MS they could be identified in the samples.

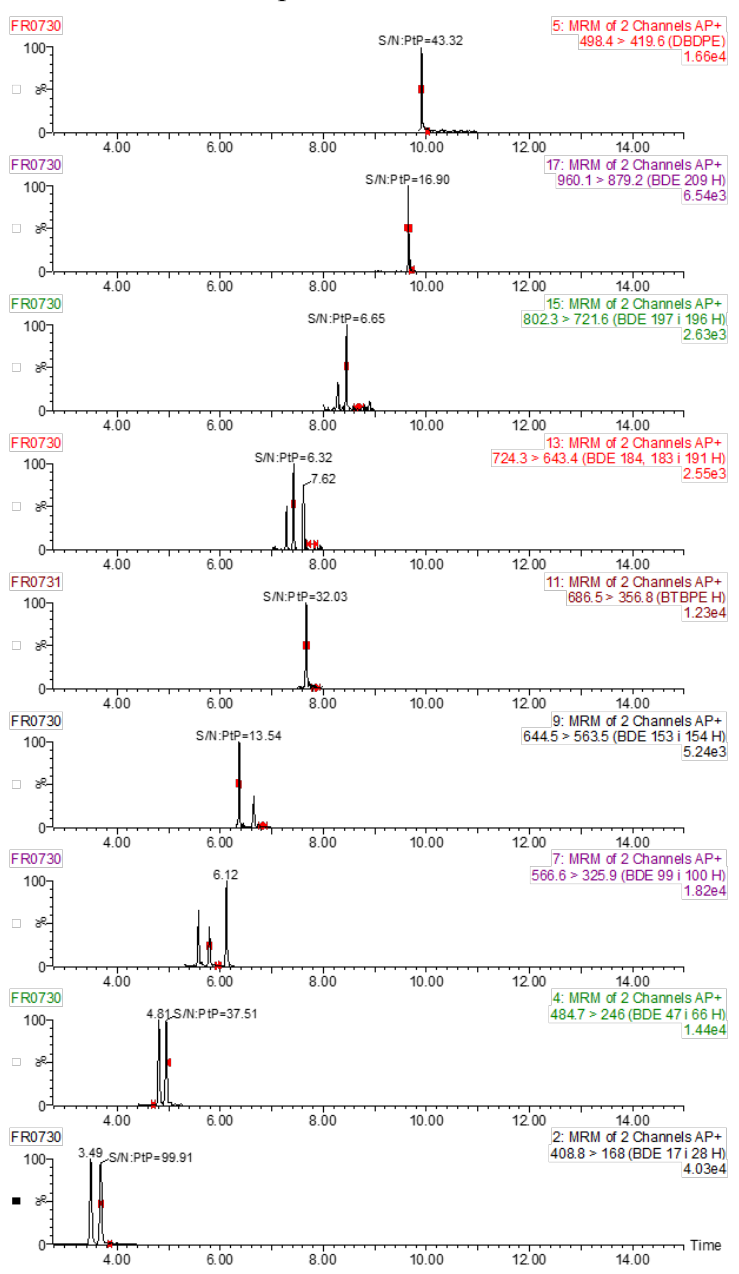

(B)

Figure 3. GC-APCI-MS/MS chromatogram of all BFRs for the concentration of $0.05 \mu \mathrm{g} / \mathrm{L}$ (except $0.1 \mu \mathrm{g} / \mathrm{L}$ for BTBPE) under (A) charge transfer conditions and (B) proton-transfer conditions. S/N:PtP: peak-to-peak signal-to-noise ratio.

Figure 4B shows a positive finding of DBDPE in a fish sample that had been previously reported as negative sample by GC-EI-MS/MS with QqQ. Up to four SRM transitions were observed by APCI showing a concentration level near or below the lowest calibration point, which illustrates the improvement in sensitivity in the analysis of real samples.

No relevant differences were found neither in the detection/identification or quantification of the samples when using the two GC-APCI approaches evaluated in this paper. As an example, Figure S-3 shows a positive finding of BDE 209 in dolphin using both methodologies, charge-transfer mode (left) and proton-transfer mode (right).

\section{CONCLUSIONS}

The use of APCI has been evaluated as alternative source for GC-MS/MS analysis of BFRs. In contrast to the EI source, (quasi)molecular ions $\left(\mathrm{M}^{+\bullet}\right.$ and/or $[\mathrm{M}+\mathrm{H}]^{+}$) were obtained as base peak of the spectrum for most compounds. Commonly, a mixture of $\mathrm{M}^{+}$ and $[\mathrm{M}+\mathrm{H}]^{+}$was observed, and both ions might be selected as precursors in a MS/MS method. The best sensitivity was reached working under charge-transfer 
conditions and using $\mathrm{M}^{+*}$ as precursor ion. This fact strongly improved sensitivity (LODs, lower than $10 \mathrm{fg}$ on-column) and selectivity compared to GC-EIMS/MS analysis. Moreover, working under chargetransfer conditions would allow the investigation of other brominated flame retardants, e.g. hexabromocyclododecane (data not shown), which elutes in the same clean-up fraction during sample treatment of PBDEs and whose ionization was dramatically affected under proton-transfer conditions

Under the conditions established in this work, some disadvantages when using other reported techniques for the sensitive determination of BFRs can be avoided. Thus, the high sensitivity observed for all PBDEs, especially for the higher brominated PBDE congeners (even better than with GC-ECNI-MS and GC-EI-HRMS), is a key aspect in the present approach. Not less important is the fact that this technique is not so expensive and requires lower maintenance costs and specialization than GC-HRMS. This paper lays the foundations for the subsequent development of an analytical procedure, which will be properly validated to set up the most relevant analytical characteristics (accuracy, precision and limits of quantification). Hopefully, the future GCAPCI-MS/MS method will notably improve the performance of the traditional GC-EI-MS/MS methodology.

\section{ASSOCIATED CONTENT}

Supporting Information as noted in the text is available free of charge on the ACS Publications website at http://pubs.acs.org.

\section{AUTHOR INFORMATION \\ Corresponding Author}

*Phone: 34-964-387339. E-mail: tportole@uji.es

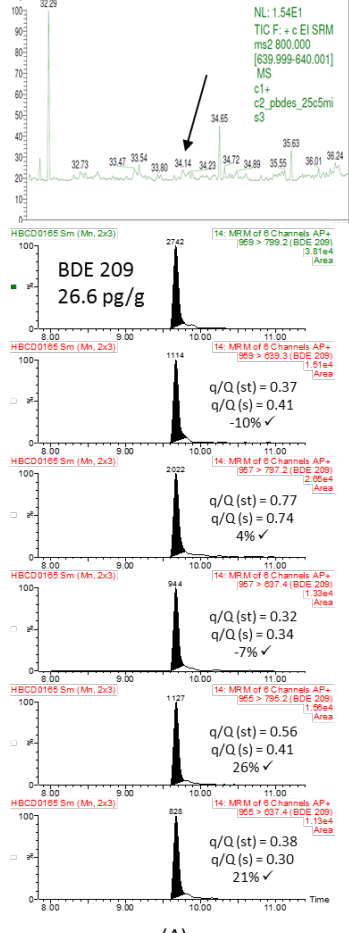

(A)

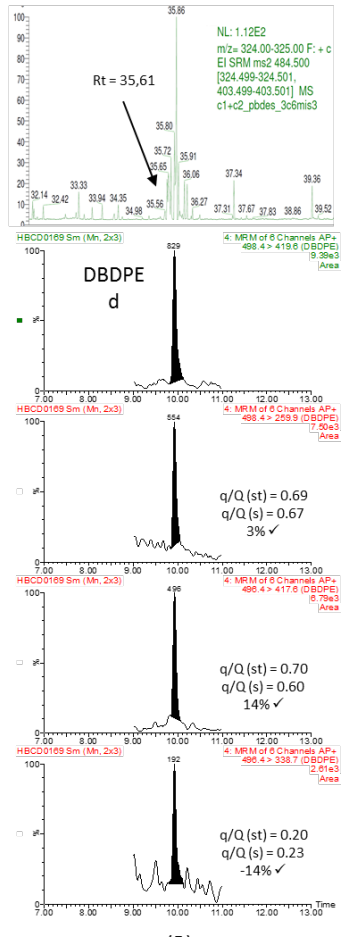

(B)
Figure 4. Positive findings in fish of (A) BDE 209 and (B) DBDPE detected and identified by applying GCAPCI-MS/MS (down) previously reported as not detected by GC-EI-MS/MS (top). d; detected, below LCL.

\section{ACKNOWLEDGMENTS}

The authors acknowledge the financial support of Generalitat Valenciana, (research group of excellence PROMETEO/2009/054 and Prometeo II 2014/023; and Collaborative Research on Environment and Food-Safety (ISIC/2012/016)). We also thank the Spanish Ministry of Economy and Competitiveness and European funding from FEDER program (project AGL2012-37201 and S2013/ABI-3028 - AVANSECAL). The authors thank Dr. José Luis Acuña and Mrs. Sonia Romero for providing the marine samples.

REFERENCES

(1) Mohr, S.; García-Bermejo, A.; Herrero, L.; Gómara, B.; Costabeber, I. H.; González, M. J. Sci. Total Environ. 2014, 472, 741-745.

(2) Cristale, J.; Quintana, J.; Chaler, R.; Ventura, F.; Lacorte, S. J. Chromatogr. A 2012, 1241, 1-12.

(3) Houde, M.; Berryman, D.; de Lafontaine, Y.; Verreault, J. Sci. Total Environ. 2014, 479-480 (1), 48-56.

(4) Wang, D.; Li, Q. X. Mass Spectrom. Rev. 2010, 29 (5), 737-775.

(5) Covaci, A.; Voorspoels, S.; de Boer, J. Environ. Int. 2003, 29 (6), 735-756.

(6) Covaci, A.; Voorspoels, S.; Ramos, L.; Neels, H.; Blust, R. J. Chromatogr. A 2007, 1153 (1-2), 145171.

(7) Stapleton, H. M. Anal. Bioanal. Chem. 2006, 386 (4), 807-817.

(8) Jinhui, L.; Yuan, C.; Wenjing, X. Environ. Sci. Pollut. Res. Int. 2015.

(9) García-Villalba, R.; Pacchiarotta, T.; CarrascoPancorbo, A.; Segura-Carretero, A.; Fernández- 
Gutiérrez, A.; Deelder, A. M.; Mayboroda, O. A. J. Chromatogr. A 2011, 1218 (7), 959-971.

(10) Galatius, A.; Bossi, R.; Sonne, C.; Rigét, F. F.; Kinze, C. C.; Lockyer, C.; Teilmann, J.; Dietz, R. Environ. Sci. Pollut. Res. Int. 2013, 20 (11), 8013-8020.

(11) Gómara, B.; Herrero, L.; González, M. J. Anal. Chim. Acta 2007, 597 (1), 121-128.

(12) Medina, C. M.; Pitarch, E.; López, F. J.; Vázquez, C.; Hernández, F. Anal. Bioanal. Chem. 2008, 390 (5), 1343-1354.

(13) Mackintosh, S. A.; Pérez-Fuentetaja, A.; Zimmerman, L. R.; Pacepavicius, G.; Clapsadl, M.; Alaee, M.; Aga, D. S. Anal. Chim. Acta 2012, 747, 67-75.

(14) Roszko, M.; Szymczyk, K.; Jędrzejczak, R. Anal. Chim. Acta 2013, 799, 88-98.

(15) Kalachova, K.; Cajka, T.; Sandy, C.; Hajslova, J.; Pulkrabova, J. Talanta 2013, 105, 109-116.

(16) . Official Journal L 065, 05/03/2014 P. 0039-0040

(17) Cervera, M. I.; Portolés, T.; López, F. J.; Beltrán, J.; Hernández, F. Anal. Bioanal. Chem. 2014, 406 (27), 6843-6855.

(18) Portolés, T.; Sancho, J. V; Hernández, F.; Newton, A.; Hancock, P. J. Mass Spectrom. 2010, 45 (8), 926-936.

(19) Portolés, T.; Mol, J. G. J.; Sancho, J. V; Hernández, F. Anal. Chem. 2012, 84 (22), 9802-9810.

(20) Portolés, T.; Mol, J. G. J.; Sancho, J. V; Hernández, F. J. Chromatogr. A 2014, 1339, 145-153.

(21) Ballesteros-Gómez, A.; De Boer, J.; Leonards, P. E. G. Anal. Chem. 2013, 85 (20), 9572-9580.

(22) Gómara, B.; Herrero, L.; Bordajandi, L. R.; González, M. J. Rapid Commun. Mass Spectrom. 2006, 20 (2), 69-74.

(23) Gómara, B.; Herrero, L.; González, M. J. Environ. Sci. Technol. 2006, 40 (24), 7541-7547.

(24) Concejero, M.; Ramos, L.; Jiménez, B.; Gómara, B.; Abad, E.; Rivera, J.; González, M. . J. Chromatogr. A 2001, 917 (1-2), 227-237.

(25) Munoz, G.; Giraudel, J.-L.; Botta, F.; Lestremau, F.; Dévier, M.-H.; Budzinski, H.; Labadie, P. Sci. Total Environ. 2015, 517, 48-56.

(26) Labadie, P.; Alliot, F.; Bourges, C.; Desportes, A.; Chevreuil, M. Anal. Chim. Acta 2010, 675 (2), 97105.

(27) Barco-Bonilla, N.; Plaza-Bolaños, P.; Tarifa, N. M. V.; Romero-González, R.; Vidal, J. L. M.; Frenich, A. G. J. Sep. Sci. 2014, 37 (1-2), 69-76. 
For TOC only

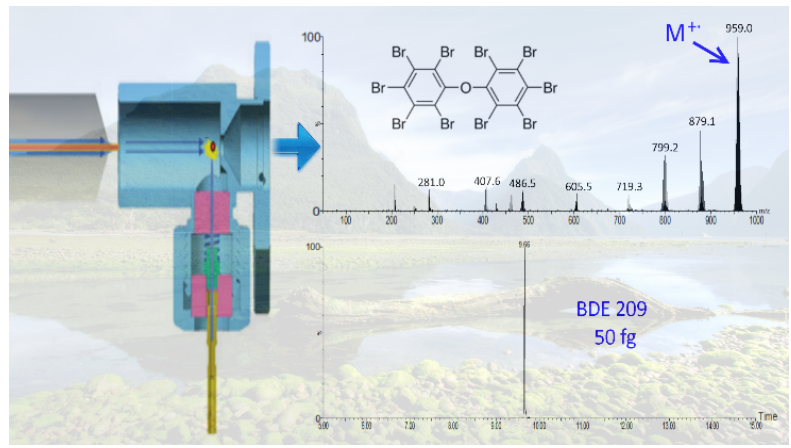

